\title{
Improving the Neurological Exam Skills of Medical Students
}

\author{
Fraser G.A. Moore, Colin Chalk
}

\begin{abstract}
Objective: Determine if distributed practice of neurological exam (NE) skills in first year medical school produces sustained improvements in the skills of second year students. Methods: A prospective, controlled, non-blinded study conducted at McGill University (class size $=180$ students). Expanded teaching of muscle stretch reflexes was provided to first year medical students. A structured examination of muscle stretch reflexes ( $\max$ score $=100$ ) was administered in second year medical school after a required two week rotation in Neurology. Results for class A (received the intervention in first year) were compared to the results for the preceding class B (had not received the intervention). Results: 77 of 177 (44\%) eligible students in class A and 69 of 166 (42\%) eligible students in class B participated. Results were analyzed separately for each of two examiners. Mean (SD) scores were 95.2 (5.6) for class A (intervention) and 81.7 (11.1) for class B (control) for the first examiner and 90.4 (8.2) for class A and 83.8 (11.7) for class B for the second examiner. Results were statistically significant (Mann-Whitney test $\mathrm{z}=5.27, \mathrm{p}<0.0001$ first examiner and $\mathrm{z}=2.67, \mathrm{p}<0.0038$ second examiner). Conclusions: Distributed practice of muscle stretch reflexes during first year medical school results in improved performance by second year medical students after their mandatory clinical rotation in neurology, even when examined up to 14 months after the intervention. This finding has implications for the teaching of the NE.
\end{abstract}

RÉSUMÉ: Améliorer les compétences des étudiants en médecine en matière d'examen neurologique. Objectif : Le but de cette étude était de déterminer si l'acquisition de compétences en matière d'examen neurologique (EN) au cours de la première année de médecine entraîne des améliorations soutenues de ces compétences chez les étudiants de deuxième année. Méthode : Une étude ouverte, prospective et contrôlée a été effectuée à l'Université McGill (classe de 180 étudiants). Les étudiants en première année de médecine ont reçu un enseignement enrichi sur les réflexes d'étirement des muscles. En deuxième année, les étudiants ont subi un examen structuré des réflexes d'étirement des muscles (noté sur 100), après un stage obligatoire en neurologie. Les résultats de la classe A (qui avait fait l'objet de l'intervention au cours de la première année) ont été comparés à ceux de la classe précédente, la classe B (qui n'avait pas fait l'objet de l'intervention). Résultats : Soixante-dix-sept (44\%) des 177 étudiants éligibles de la classe A et 69 (42\%) des 166 étudiants éligibles de la classe B ont participé à l'étude. Les résultats attribués aux étudiants par chacun des deux examinateurs ont été analysés séparément. Le score moyen de la classe A (intervention) était 95,2 (ET 5,6) et celui de la classe B (témoin) 81,7 (ET $11,1)$ selon l'évaluation du premier examinateur et 90,4 (ET 8,2) pour la classe A et 83,8 (ET 11,7) pour la classe B selon l'évaluation du deuxième examinateur. Les résultats étaient statistiquement significatifs (test de Mann-Whitney : $\mathrm{z}=5,27 ; \mathrm{p}<0,0001$ pour le premier examinateur et $\mathrm{z}=2,67$; p $<0,0038$ pour le second examinateur). Conclusions : Le fait de dispenser l'enseignement sur les réflexes d'étirement des muscles au cours de la première année de médecine se traduit par une meilleure performance des étudiants de deuxième année après leur stage clinique obligatoire en neurologie, même si l'examen a lieu dans un délai allant jusqu'à 14 mois après l'intervention. Ces constatations ont des implications en ce qui concerne l'enseignement de l'EN.

Can. J. Neurol. Sci. 2012; 39: 83-86

Graduating medical students lack confidence in the neurological examination (NE), despite knowledge of the essential components of a basic $\mathrm{NE}^{1}$. Students may have difficulty learning the skilled parts of the NE and could benefit from more frequent instruction. This would require evidence that such instruction results in improved retention of NE skills.

In the education literature "distributed practice", in which knowledge or a skill is taught in multiple sessions separated in time, provides better retention of learning than "massed practice", in which a single more prolonged session is used ${ }^{2}$. However, the literature consists of studies in which practice occurs over a short time (typically 24 hours or less), followed by an evaluation of the effect. This is not optimal for assessing retention of learning ${ }^{2}$. Studies of distributed practice in the medical literature most commonly address surgical skills with distributed practice over one ${ }^{3}$ or several months ${ }^{4-5}$, and outcomes evaluated immediately after completion ${ }^{3}$ or up to four months later ${ }^{4-5}$.

We sought to determine if the technique of distributed practice could be applied to the teaching of the NE. Specifically, we wanted to know if NE skills taught to first year medical students would be retained over a more prolonged time period, and would improve their performance after completing a mandatory second year clinical rotation in neurology. We

From the Department of Neurology and Neurosurgery (FGAM), Department of Medicine (CC), Centre for Medical Education, McGill University, Montréal, Quebec, Canada.

Received May 19, 2011. Final Revisions Submitted July 12, 2011.

Correspondence to: Fraser Moore, 3755 Côte-Sainte-Catherine E-005, Montréal, Quebec, H3T 1E2, Canada. 


\begin{tabular}{|c|c|c|c|}
\hline & 2008 & 2009 & 2010 \\
\hline Class A & & 1st year medical school & 2nd year medical school \\
(Intervention) & & Neuroanatomy & Neurology \\
Expanded teaching & Outcome measure \\
\hline Class B & $\begin{array}{c}\text { 1st year medical } \\
\text { school }\end{array}$ & 2nd year medical school & \\
(Control) & Neuroanatomy & Neurology & \\
& Standard teaching & Outcome measure & \\
\hline
\end{tabular}

Figure 1: Study design.

focused on muscle stretch reflexes as a simple, easy to evaluate motor task.

\section{Methods}

\section{The Status Quo}

Medical students at McGill University participate in a course on the nervous system in March and April of first year. The emphasis is on neuroanatomy with some clinical correlation in lectures and in six case-based small groups. One lecture is given on the anatomy and physiology of spinal reflexes. The clinical application of testing muscle stretch reflexes as part of the NE is explained, but the technique of testing reflexes is not taught. In January of second year students receive one small group teaching session on the neurological examination as part of their "introduction to clinical skills" course. Between February and June of second year students participate in a two week clinical course in Neurology. Common clinical problems are discussed and the neurological examination is demonstrated and practiced in groups of two to six students. Students also spend time observing in clinics, on the ward, and as part of the consultation service.

\section{The Intervention}

In 2009 first year students (class A) were provided with expanded teaching on muscle stretch reflexes. The technique of testing reflexes was specifically taught during the lecture on spinal reflexes. Students were encouraged to practice testing reflexes on their own and during their small group teaching sessions (when they were supervised by a neurologist or senior neurology resident). As part of the final examination for the course, every student was required to demonstrate their ability to test one of the five standard muscle stretch reflexes. Students had previously been told that they would be examined and had been provided with a list of criteria that the examiners would be

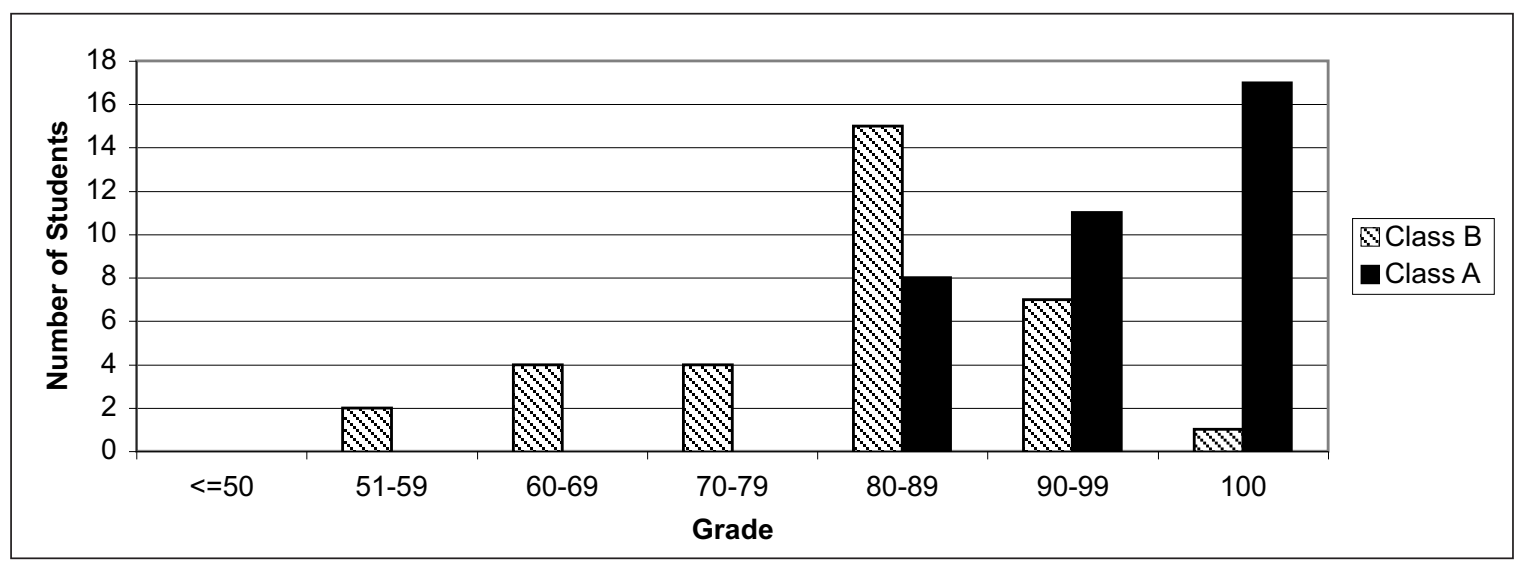

Figure 2: Results for first examiner (FM). Class A received the intervention (expanded teaching on muscle stretch reflexes). Class $B$ is the control group. 


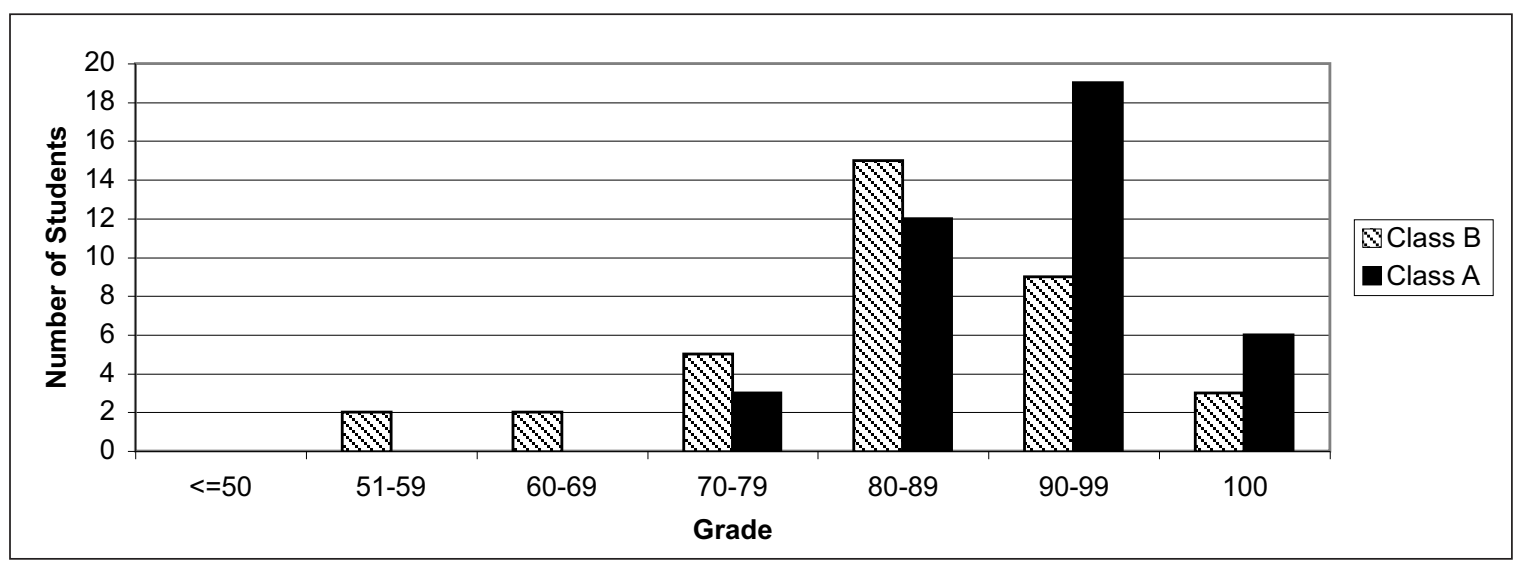

Figure 3: Results for second examiner (CC). Class A received the intervention (expanded teaching on muscle stretch reflexes). Class B is the control group.

looking for. This examination formed part of the intervention and was not the outcome.

\section{Outcome Measure}

Approximately one year later (range 10-14 months), between February and June 2010, the authors examined a subset of the students of class A again, at the end of their second year neurology rotation (Figure 1). Students are randomly assigned to complete this rotation at one of five hospitals. Two of the hospitals served as examination sites, allowing us to examine approximately half of the class. Students were asked to demonstrate each of the five commonly tested muscle stretch reflexes (biceps, triceps, brachioradialis, quadriceps, gastrocnemius) on one side of the body. Students demonstrated the reflexes on each other. Each student received a grade out of 100. Each reflex was worth 20 marks. When testing each reflex students received either 0 (unacceptable) or 4 marks (satisfactory) in each of five categories; positioning of the subject's limb, contacting the correct site, correctly gripping the reflex hammer, swinging the reflex hammer through an appropriate arc of motion, and using sufficient force. This examination was not blinded. Blinding would have required the training of examiners who were unaware of the intervention. This was felt to be impractical as many McGill neurologists and neurology residents participate in teaching during the first year nervous system course in which the intervention occurred.

\section{Control Group}

The control group consisted of students in the preceding class B tested in an identical manner between February and June of 2009 , but whom had only received standard teaching on muscle stretch reflexes when they were in first year (Figure 1). The clinical application of testing muscle stretch reflexes was explained during the lecture on spinal reflexes but the technique of testing reflexes was not taught. Students were not asked to practice testing reflexes on their own or during their small group teaching sessions in first year, and they were not examined on stretch reflexes at the end of their first year course.
All students provided written consent to participate and the study was approved by the McGill University institutional review board.

\section{Statistical Analysis}

Descriptive statistics were calculated from the results of class A and class B. The distribution of scores in each class was compared with a Mann-Whitney test. As it was expected that there could be differences in grading between the two examiners, the results were analyzed separately for each examiner.

\section{RESUlTS}

A total of 77 of 177 (44\%) eligible students in class A and 69 of $166(42 \%)$ eligible students in class B participated in the study. As stated in the methods section, these students represented the subset that were randomly assigned to complete their second year neurology rotation at two of five hospital sites. No students declined to participate in the study.

For the first examiner (FM) mean (SD) scores were 95.2 (5.6) for class A (intervention) and 81.7 (11.1) for class B (control). For the second examiner (CC) scores were 90.4 (8.2) for class A and 83.8 (11.7) for class B. Comparison of scores with a Mann Whitney test showed a statistically significant difference between class A and class B for both the first $(\mathrm{z}=5.27, \mathrm{p}<$ $0.0001)$ and second examiners $(z=2.67, p<0.0038)$. The distribution of the results is presented in Figure 2 (first examiner) and Figure 3 (second examiner). No difference was seen (for a given class and examiner) between subjects who were tested early (February) and later (June) (data not shown).

\section{Discussion}

Our results show that distributed practice of muscle stretch reflexes during first year medical school results in improved performance by second year medical students after their mandatory clinical rotation in neurology, even when examined up to 14 months after the intervention. Only a few previous studies have shown the benefit of distributed practice in medical 
education $^{3-6}$. The benefits were assessed immediately $y^{3,6}$ or within four months $s^{4-5}$ after completion of distributed practice. Our study has shown that skills acquired with distributed practice can result in improved performance even when assessed more than one year later.

To our knowledge the use of distributed practice has never been shown for either Neurology in general or the NE in particular. Our results have important implications for the teaching of the NE. Distributed practice of parts or all of the NE throughout medical school, and beginning as early as first year, may improve student's examination skills and lead to improved confidence in the NE. Our methods could be easily applied in any medical school and would not require a significant time commitment. In fact, if senior medical students arrive for clerkship or elective rotations in Neurology with increased confidence in their NE skills then they would be able to work more independently and require less hands-on instruction in the NE.

The major limitation of this study is that the two examiners were not blinded to the intervention. However, a concerted effort was made to be as objective as possible in assessing students and scores were based on clearly defined criteria. Other limitations include variability between tutors in the small group sessions in first year (when the students were learning how to examine reflexes) and the variable time between the intervention and the outcome (from 10 to 14 months). However, variability between tutors would tend to negate any benefit of the intervention while the range of time intervals was balanced between intervention and control groups. A final limitation is the potential variability in the experience of the students during their second year neurology rotation, in terms of the selection of patients each student saw and the instruction they received on the ward. However, one would expect that the range of experiences would vary in a similar manner within each group (class A and class B) and would not affect the results.

\section{ACKNOWLEDGEMENT}

The authors thank their colleagues at the McGill Centre for Medical Education for their suggestions and feedback, and the students for their participation.

\section{Disclosure}

Dr. Moore has participated in multiple sclerosis clinical trials sponsored by EMD Serono and Bayer, and received funding from EMD Serono for the organization of a one-day multiple sclerosis teaching course for neurology residents.

\section{REFERENCES}

1. Moore FGA, Chalk C. The essential neurological examination. What should medical students be taught? Neurology. 2009;72: 2020-3.

2. Donovan JJ, Radosevich DJ. A meta-analytic review of the distribution of practice effect: Now you see it, now you don't. J Appl Psychol. 1999;84(5):795-805.

3. Moulton CAE, Dubrowski A, MacRae H, Graham B, Grober E, Reznick R. Teaching surgical skills: What kind of practice makes perfect? A randomized, controlled trial. Ann Surg. 2006;244: 400-9.

4. Mitchell EL, Lee DY, Sevdalis N, et al. Evaluation of distributed practice schedules on retention of a newly acquired surgical skill: a randomized trial. Am J Surg. 2011;201:31-9.

5. Stefanidis D, Korndorffer JR, Markley S, Sierra R, Scott DJ. Proficiency maintenance: Impact of ongoing simulator training on laparoscopic skill retention. J Am Coll Surg. 2006;202: 599-603.

6. Kerfoot BP, DeWolf WC, Masser BA, Federman DD. Spaced education improves the retention of clinical knowledge by medical students: a randomised controlled trial. Med Educ. 2007;41:23-31. 